\title{
A profissão de escritora no Brasil: uma leitura das crônicas de Clarice Lispector $^{1}$
}

Ana Cristina Coutinho Viegas ${ }^{2}$

Resumo: Escritora profissional, pressionada por questões financeiras, Clarice Lispector não consegue resistir a não trabalhar na imprensa e nos legou um histórico bastante razoável de textos em jornais e revistas. Esta pesquisa se volta para as crônicas da autora publicadas entre 1967 e 1973, no Jornal do Brasil, postumamente reunidas no livro A descoberta do mundo. Definida como gênero híbrido, forma fronteiriça entre jornalismo e literatura, a crônica, muitas vezes, constitui um espaço de grande relevância para encenar subjetividades e propor reflexões metalinguísticas. Mesmo tratando do trivial e assumindo uma postura despretensiosa, muitos desses textos constituem importante exercício de crítica e autocrítica. No caso de Clarice Lispector, o caráter transgressor presente em seus romances e contos encontra-se também nesses pequenos textos produzidos com hora marcada.

Palavras-chave: Clarice Lispector. Crônicas. Gêneros literários.

Em carta de março de 1959, em que trata de uma possível e demorada publicação de um livro de contos pelo Ministério da Educação, Clarice Lispector faz uma proposta a José Simeão Leal:

[...] estou pronta a devolver os dois ou três mil cruzeiros, em troca do direito de dispor de meus originais. Estou precisando de dinheiro e quero vender os contos separadamente a jornais ou revistas (MONTERO, 2002, p. 243).

O final da década de 50 e os primeiros anos da década de 60 constituem um momento particularmente difícil na vida pessoal e profissional de Clarice. No primeiro semestre de 59, a escritora se separa do marido, volta para o Brasil com os dois filhos e enfrenta obstáculos para editar seus livros.

A angústia de esperar pela publicação de seus textos não se encontra apenas na correspondência com os editores. É explicitada também em cartas para os amigos. Em

\footnotetext{
${ }^{1} \mathrm{O}$ artigo foi uma palestra pronunciada no III Seminário de Estudos Literários do Programa de Pós-Graduação em Estudos Literários da Faculdade de Formação de Professores da UERJ, nos dias 23 e 24 de outubro de 2012.

${ }^{2}$ Doutora em Teoria Literária pela UFRJ. Professora do Departamento de Língua Portuguesa e Literaturas do Colégio Pedro II desde 1997. Professora do Mestrado Profissional em educação Básica do Colégio Pedro II. Atualmente coordena a área de Português no Programa de Residência Docente na Pós-Graduação da mesma instituição de ensino. E-mail: anacristinaviegas @ terra.com.br.
} 
$\begin{array}{llllllll}\text { R } & \text { E } & \text { V } & \text { I } & \text { S } & \text { T } & \text { A } & \text { N. 24-2012.2-ANA CRISTINA COUTINHO VIEGAS }\end{array}$

dezembro de 1956, por exemplo, escreve a Fernando Sabino: “[...] uma coisa escrita e não publicada me dá muita frustração, sinto como moça que faz enxoval de casamento e guarda num baú. Antes casar mal que não casar, é horrível ver enxoval amarelecendo" (SABINO, 2001, p. 180).

Em outra carta ao mesmo amigo, afirma: "[...] Esperas me fazem mal, me atrapalham, fazem de mim uma impaciente. Não tem que ser bom editor, tem que ser rápido e me deixar então livre" (SABINO, 2001, p. 128). (Grifos de Lispector).

De acordo com Nádia Batella Gotlib, em Clarice: uma vida que se conta, o escritor Paulo Francis, em depoimento concedido à imprensa, logo após a morte da escritora em 1977, relembra que, em 1959, ela não tinha editor no Brasil:

Tinha fama, sim, mas entre intelectuais e escritores. Os editores a evitavam como a praga, o que se devia [...] ao caráter 'moderno' da sua literatura que não seguia o 'realismo socialista' e representava a realidade em relances, indireta e indutivamente (GOTLIB, 1995, p. 310).

Adjetivos como "metafísica" e "hermética" sempre acompanharam a crítica sobre a obra de Clarice, uma escritora que "perdia de vista o fato social". Seu primeiro romance, Perto do coração selvagem, foi recebido com reservas por Álvaro Lins, que o considerou uma "experiência incompleta", que se aproximava da "literatura feminina", a qual, segundo o ensaísta, teria como característica básica um confessionalismo excessivo (ROCHA, 2003, p. 48). Porém, com o passar do tempo, começou a ganhar destaque uma crítica que via, nessa "experiência incompleta", seu caráter transgressor. Mesmo A hora da estrela, seu último romance, que parece abrir o texto de Clarice a uma tematização social mais explícita, se mantém fiel à proposta estética inaugurada nos anos 40 ao tecer, paralelamente à história da migrante nordestina Macabéa, uma narrativa sobre a crise da representação encenada nas interrogações e nos impasses do narrador Rodrigo S. M.

Em 1958, ainda vivendo nos Estados Unidos, Clarice recebe convite para publicar na Revista Senhor, periódico que seria lançado em março de 1959 e que marcaria época na imprensa brasileira servindo como importante espaço para divulgar nossa produção intelectual e literária. No primeiro número, sai o conto "A menor mulher do mundo", que deu início a uma colaboração que se estenderia até 1964.

Senhor é fruto de um período em que o processo de desenvolvimento econômico, a afirmação dos valores democráticos e a efervescência cultural estimularam a transformação 
$\begin{array}{llllllll}\text { R } & \text { E } & \text { V } & \text { I } & \text { S } & \text { T } & \text { A } & \text { N. 24-2012.2-ANA CRISTINA COUTINHO VIEGAS }\end{array}$

dos padrões da imprensa brasileira, propiciando alterações em diferentes periódicos e possibilitando a criação de novas publicações. Com a turbulência da vida política do país e a retração dos negócios no início de 64, a revista tornou-se inviável e fechou.

Nos cinco anos de sua existência, contudo, Senhor publicou ficção nacional inédita, como as novelas "Meu tio, o Iauaretê" (março de 1961) e "A história do homem do pinguelo" (março de 1962), de Guimarães Rosa, e que hoje compõem o livro póstumo Estas histórias. Contos de Clarice Lispector eram frequentes. Já no primeiro número, publicou-se "A menor mulher do mundo", posteriormente incluído no livro Laços de família. O quarto número publicou a então inédita novela de Jorge Amado, As duas mortes de Quincas Berro d'água. Foi responsável também por lançar escritores importantes, como Rubem Fonseca.

Enquanto romancista, Clarice Lispector não consegue publicar seus livros, já a contista tende a ganhar cada vez mais leitores, que leem com regularidade o charmoso e importante periódico. Seus textos, assim como de outros colaboradores, recebem cuidado gráfico e são acompanhados, muitas vezes, por ilustrações de excelente qualidade, como é o caso de "Feliz aniversário", texto publicado inicialmente no número 8 de outubro de 1959, com sete belos desenhos de Anísio Medeiros.

Pressionada por questões financeiras, Clarice Lispector não consegue resistir ao trabalho jornalístico e, além de sua participação na revista Senhor, constrói um histórico bastante razoável em jornais e revistas. Podemos lembrar, dentre outras, sua colaboração como cronista, entre 1967 e 1973 no Jornal do Brasil. Em 1968, ingressa na revista Manchete e cabe a ela entrevistar pessoas de destaque do mundo cultural e artístico. A obra De corpo inteiro, cuja primeira edição data de 1975, constitui uma coletânea desses textos. Na entrevista com Tom Jobim, conta que o conheceu no Primeiro Festival de Escritores, quando foi lançado o romance $A$ maçã no escuro e que o compositor, fazendo brincadeiras, segurava o livro na mão e perguntava: “Quem compra? Quem quer comprar?”. Durante a mesma entrevista, Clarice afirma: "Sofro se isto acontecer, que alguém me leia apenas no método do vira-página dinâmico. Escrevo com amor e atenção e ternura e dor e pesquisa, e queria de volta, como mínimo, uma atenção e um interesse como o seu, Tom” (LISPECTOR, 1999b, p. 119).

Após esse breve intróito, este artigo passa, a seguir, à investigação das crônicas escritas por Clarice Lispector no Jornal do Brasil, entre 1967 e 1973, postumamente reunidas na coletânea A descoberta do mundo. 


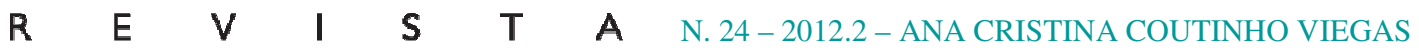

De acordo com diferentes críticos, a crônica, em seu sentido atual, constitui um gênero brasileiro por excelência, devido à originalidade e à popularidade com que aqui se desenvolveu. Ao longo de um percurso que vem desde a seção "Ao correr da pena", no Correio Mercantil, para a qual escrevia semanalmente José de Alencar, a crônica foi deixando de lado a intenção de informar e comentar - intenção atribuída a outros textos que circulam na imprensa -, tornou-se mais leve, afastou-se da lógica argumentativa e penetrou no reino da poesia (CANDIDO, 1992).

Mesmo tratando do trivial, a crônica deixa entrever a preocupação com grandes questões. No limite entre literatura e jornalismo, evita o espírito de reportagem, visto que, se, para o jornalista, o fato constitui um fim, para o cronista é apenas um meio. Muitas vezes, assume a forma de um breve ensaio, na medida em que aborda criticamente diversos temas, inclusive a própria literatura, propondo reflexões sobre o ato de escrever. O grande número de antologias recém-publicadas atesta a boa receptividade do gênero entre os leitores atuais e evidencia seu prestígio como objeto de estudo.

Se, por um lado, está ligada ao efêmero, por outro, a crônica tem o papel de preservar esse efêmero e pode até mesmo adquirir valor de documento de uma época. Na passagem do jornal para o livro, seu caráter circunstancial é amenizado, até mesmo porque aquelas que tendem ao envelhecimento não são incluídas nessas publicações. Existem, entretanto, outras maneiras de analisá-la além do ponto de vista histórico, já que, entre outros aspectos, o cronista recoloca para seus leitores a questão dos gêneros literários.

A discussão sobre o que é um texto literário é bastante complexa nos estudos literários contemporâneos. Outra questão enfrentada pelos estudiosos de literatura é a interrelação dos gêneros literários, cada vez mais intensa a partir do modernismo, o que gerou também alguns novos e importantes estudos sobre o tema.

A longa história da teoria dos gêneros literários pode ser resumida em três grandes etapas: a clássica (de Platão e Aristóteles até o neoclassicismo); a romântica; e a do formalismo russo até os nossos dias. As diferentes teorias sobre a questão dos gêneros giram em torno de um denominador comum: o que representa o literário e como essa representação se produz.

No século XX, alguns teóricos ganham destaque nos estudos sobre os gêneros. Na sua influente Teoria da Literatura, de 1942, René Wellek e Austin Warren chamavam atenção para o fato de que os gêneros literários são formas discursivas históricas. Destacam o fato de 
$\begin{array}{llllllll}\text { R } & \text { E } & \text { V } & \text { I } & \text { S } & \text { T } & \text { A } & \text { N. 24-2012.2-ANA CRISTINA COUTINHO VIEGAS }\end{array}$

que a moderna teoria dos gêneros literários não é normativa, mas descritiva. Trata-se, portanto, de uma metodologia diferente daquela adotada pelas poéticas clássicas, que impunham regras de criação textual e determinavam as espécies literárias que deveriam ser cultivadas.

Em seu Conceitos fundamentais da poética, Emil Staiger, publicado em 1952, afastando-se de classificações fechadas e substantivas, adota os adjetivos "lírico", "épico" e "dramático". Com eles, pode-se falar, por exemplo, em romances dramáticos, o que significa dizer apenas que o dramático está aí de algum modo expresso. Analisa os traços dos gêneros em suas mais fortes presenças, mas sempre lembrando que nenhuma obra é totalmente lírica, épica ou dramática, não só por não apresentar apenas características de um único gênero, mas também porque essas características não se projetam sempre da mesma maneira na constituição da linguagem.

Convém destacar também a contribuição da Estética da Recepção. Hans Robert Jauss volta-se para os gêneros literários, ressaltando que toda obra está vinculada a um conjunto de informações e a uma situação especial de apreensão e, por isso, pertence a um gênero, na medida em que admite um horizonte de expectativas, isto é, alguns conhecimentos prévios que conduziriam à sua leitura. Os gêneros formariam a redundância necessária à recepção e à situação da obra e apresentariam marcas variáveis, não totalmente conscientes, que serviriam de orientação à leitura e à produção.

No domínio literário, reina a pluralidade de discursos e gêneros em permanente interação e germinação criativa. Deve-se notar ainda que os próprios autores não pretendem deixar suas obras caírem em modelos preconcebidos. Muitos títulos de romances, por exemplo, jogam com os limites da definição do gênero a que devem pertencer. Podemos citar, entre tantos outros, o Ensaio sobre a cegueira, de Saramago. O mesmo procedimento se encontra em livros de contos, como é o caso, por exemplo, da Breve história do espírito, de Sérgio Sant'Anna.

As dificuldades para se agrupar os textos em gêneros adquirem, no caso de Clarice, um traço especial, uma vez que, resistindo a critérios de padronização, a própria autora rompe deliberadamente com paradigmas textuais. "Feliz aniversário", por exemplo, é apresentado na revista Senhor como novela e, posteriormente, no livro Laços de família, como conto. Crônicas escritas semanalmente para o Jornal do Brasil foram publicadas como contos, nos 
anos 70, no livro Felicidade clandestina. Em texto de 1971, Clarice (1999a, p. 542) afirma: "Gêneros não me interessam mais".

Em texto de 1971, Clarice dirá: “[...] isto aqui não é crônica coisa nenhuma. Isto é apenas. Não entra em gênero. Gêneros não me interessam mais" (LISPECTOR, 1999a, p. 347).

Três anos antes, em texto intitulado "Ser cronista", Clarice especula sobre uma possível definição para o gênero:

Crônica é um relato? É uma conversa? É o resumo de um estado de espírito? Não sei, pois antes de começar a escrever para o Jornal do Brasil, eu só tinha escrito romances e contos. Quando combinei com o jornal escrever aqui aos sábados, logo em seguida morri de medo. Um amigo que tem voz forte, convincente e carinhosa, praticamente intimou-me a não ter medo. Disse: escreva qualquer coisa que lhe passe pela cabeça, mesmo tolice, porque coisas sérias você já escreveu, e todos os seus leitores hão de entender que sua crônica semanal é um modo honesto de ganhar dinheiro. No entanto, por uma questão de honestidade para com o jornal, que é bom, eu não quis escrever tolices. As que escrevi, e imagino quantas, foi sem perceber (LISPECTOR, 1999a, p. 112).

As necessidades de ordem financeira que a levam a escrever na imprensa também são abordadas em outras crônicas: "Pagam-me para eu escrever. Eu escrevo, então" (LISPECTOR, 1999a, p. 341).

Quanto à questão do gênero, normalmente tende-se a diferenciar a crônica do conto, por exemplo, pelo aprofundamento maior das personagens no caso deste último. As tentativas de caracterização não impedem, entretanto, que, em certos casos, fique impossível fazer a distinção entre os dois gêneros. Basta lembrar o exemplo de crônicas escritas semanalmente por Clarice Lispector para o Jornal do Brasil e publicadas como contos, nos anos 70, no livro Felicidade clandestina ${ }^{3}$. A própria autora declara em uma de suas crônicas: "Sei que o que escrevo aqui não se pode chamar de crônica nem de coluna nem de artigo" (LISPECTOR, 1999a, p. 81).

Escritas em primeira pessoa, essas narrativas de cunho autobiográfico que compõem Felicidade clandestina dão espaço a reflexões sobre a vida e também sobre a própria atividade literária. Traços da Clarice ficcionista também estão na crônica, entre eles as preocupações com a escrita.

\footnotetext{
${ }^{3} \mathrm{O}$ mesmo procedimento é adotado por Clarice também com relação ao romance. A crônica "Noite na montanha" foi deslocada para o romance Uma aprendizagem ou O livro dos prazeres (Cf. ROCHA, 2007, p. 56).
} 
$\begin{array}{llllllll}\mathbf{R} & \mathbf{E} & \boldsymbol{V} & \mathbf{I} & \mathbf{S} & \mathbf{T} & \mathbf{A} & \text { N. 24-2012.2-ANA CRISTINA COUTINHO VIEGAS }\end{array}$

Vivemos em uma sociedade do espetáculo em que ganha espaço cada vez maior o falar de si. Em contrapartida, percebe-se um movimento teórico voltado para a problematização do sujeito nessa sociedade e, no que nos interessa mais de perto, na literatura. Esse pensamento vem acompanhado por um olhar atento na direção de gêneros antes considerados "menores" como crônicas, diários e cartas - por permanecerem na fronteira entre o literário e o nãoliterário, apontarem mais diretamente para a chamada "realidade" e constituírem discursos relacionados com o "eu" que escreve.

Segundo Carlos Heitor Cony, "temos a crônica esportiva, a social, a policial, a política, a econômica. Elas se diferenciam do artigo porque são centradas num eixo permanente: o 'eu' do autor. Daí que o gênero é romântico por definição e necessidade” (CONY, 1998, s/p).

No que se refere ao leitor, o pacto que se estabelece tem um caráter de maior proximidade, maior referencialidade do que em outros gêneros como o romance. Mesmo assim, o cronista faz do seu texto um espaço para encenar uma subjetividade. Naquele espaço regularmente preenchido no jornal, constrói uma figura de autor que vai ganhando contornos de um cidadão comum, que mantém, em tom de conversa, uma certa intimidade com seu público. Este pode acompanhá-lo em ações cotidianas, como mostra o seguinte fragmento de uma crônica de Clarice, em que o leitor pode visualizar a autora em sua rotina de trabalho: “Agora vou interromper para acender um cigarro. Talvez volte à máquina ou talvez pare por aqui mesmo [...]" (LISPECTOR, 1999 a, p. 341).

Nesses textos para jornal, embora relembre acontecimentos e experiências pessoais, a cronista o faz de forma discreta, contida e se inquieta com a exposição de sua intimidade. Essa preocupação se torna explícita, por exemplo, na crônica "Viajando por mar" ( $1^{\mathrm{a}}$ parte):

Nota: um dia, telefonei para Rubem Braga, o criador da crônica, e disse-lhe desesperada: 'Rubem, não sou cronista, e o que escrevo está se tornando excessivamente pessoal. O que é que eu faço?' Ele me disse: 'É impossível, na crônica, deixar de ser pessoal'. Mas eu não quero contar minha vida para ninguém: minha vida é rica em experiências e emoções vivas, mas não pretendo jamais publicar uma autobiografia [...] (LISPECTOR, 1999 a, p. 349).

Embora consciente da inevitabilidade do caráter pessoal da crônica, Clarice recusa o tom confessional. Na crônica "Escrever para jornal e escrever livro", publicada em 29 de julho de 1972, a autora aborda a questão do pacto de leitura: 


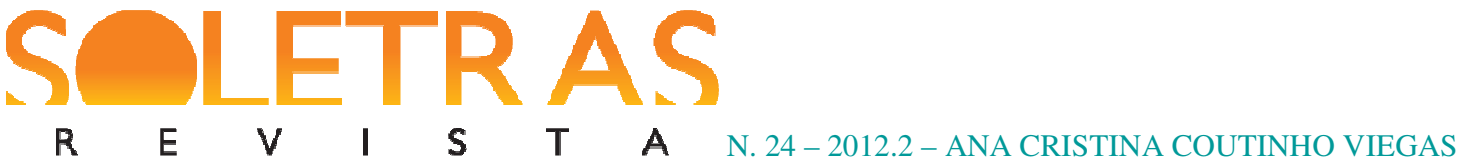

A compreensão do leitor depende muito de sua atitude na abordagem do texto, de sua predisposição, de sua isenção de idéias preconcebidas. E o leitor de jornal, habituado a ler sem dificuldade o jornal, está predisposto a entender tudo. E isto simplesmente porque 'jornal é para ser entendido' [...] (LISPECTOR, 1999a, p. 421).

Na crônica “Ao correr da máquina”, publicada em 17 de abril de 1971, a autora também reflete, sem parecer disposta a seguir modelos, sobre o seu processo de criação e o que se espera de um texto escrito para um jornal:

A propósito de uma pessoa de quem estou me lembrando agora e que usa uma pontuação completamente diferente da minha, digo que a pontuação é a respiração da frase. Acho que já disse uma vez. Escrevo à medida de meu fôlego. Estarei sendo hermética? Porque parece que em jornal se tem de ser terrivelmente explícito. Sou explícita? (LISPECTOR, 1999a, p. 341)

O adjetivo "hermética", usado para caracterizar sua escrita em certos momentos da crítica serve até mesmo de título para uma de suas crônicas:

Ganhei o troféu da criança-1967, com meu livro infantil $O$ mistério do coelho pensante. Fiquei contente, é claro. Mas muito mais contente ainda ao me ocorrer que me chamam de escritora hermética. Como é? Quando escrevo para crianças, sou compreendida, mas quando escrevo para adultos fico difícil? [...] (LISPECTOR, 1999 a, p. 79).

Há outras crônicas em que trata das diferenças entre escrever para jornal e escrever para livro. Em texto de 29 de julho de 1972, afirma: [...] eu valorizo muito mais o que escrevo em livros do que o que escrevo para jornais - isso sem, no entanto, deixar de escrever com gosto para o leitor de jornal e sem deixar de amá-lo (LISPECTOR, 1999a, p. 421).

Segundo crônica de 2 de maio de 1970,

Escrever para jornal não é tão impossível: é leve, tem que ser leve, e até mesmo superficial: o leitor, em relação a jornal, não tem vontade nem tempo de se aprofundar.

Mas escrever o que se tornará depois um livro exige às vezes mais força do que aparentemente se tem (LISPECTOR, 1999a, p. 286).

A crônica apresenta-se como uma atividade lateral de grande parte de nossos escritores. No caso de Clarice, valorizar mais o livro não altera, contudo, a densidade de suas crônicas, 


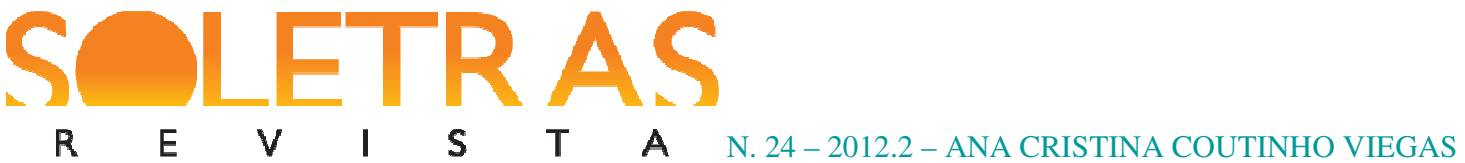

nem impede que textos, personagens e situações transitem do jornal para seus contos e romances.

O jornal também é espaço para reflexões críticas sobre os seus romances:

Bem sei o que é o chamado verdadeiro romance. No entanto, ao lê-lo, com suas tramas de fatos e descrições, sinto-me apenas aborrecida. E quando escrevo não é o clássico romance. No entanto, é romance mesmo [...] (LISPECTOR, 1999a, p. 306).

Ou para responder a críticas sobre eles:

Prezado senhor X,

Encontrei uma crítica sua sobre o livro $A$ cidade sitiada [...] $\mathrm{O}$ que me espanta - e isto certamente vem contra mim - é que a um crítico escapem os motivos maiores de meu livro [...] Não se torna evidente para mim que todos esses movimentos íntimos do livro, e mais outros que o completam, foram submergidos pelo que o senhor chama de 'magia da frase'. Desde o primeiro livro, aliás, fala-se nas minhas 'frases'. Não tenha o senhor dúvida, no entanto, de que desejei - e consegui, por Deus - qualquer coisa através delas, e não a elas mesmas.

Chamar de 'verbalismo' uma vontade dolorosa de aproximar o mais possível as palavras do sentimento - eis o que me espanta [...] (LISPECTOR, 1999 a, p. 272).

A preocupação com o leitor de seus livros também se encontra explicitada em crônicas como "Uma experiência ao vivo", de 1970:

Antes de ter submetido meu livro de história infantil ao editor João Rui Medeiros, da José Álvaro Editora, fiz um teste com uma criança de cinco anos, outra de sete, outra de dez e a quarta de 12 anos, todas reunidas num só grupo. A leitura foi feita por um amigo meu que lê bem. Minha história sobre um coelho pensante tocou as quatro idades de modo diverso e a leitura era freqüentemente interrompida por sugestões e perguntas [...] Para mim valeu por uma noite de autógrafos mais real que as reais: a comunicação se fez, sentimo-nos unidos pelo coelho pensante, pelo calor mútuo, pela liberdade sem medo [...] (LISPECTOR, 1999 a, p. 305).

Voltando às considerações sobre o "eu" que escreve, Diana Klinger, em seu livro Escritas de si, escritas do outro, afirma que

[...] tanto os textos ficcionais quanto a atuação (a vida pública) do autor são faces complementares da mesma produção de uma subjetividade, instâncias 


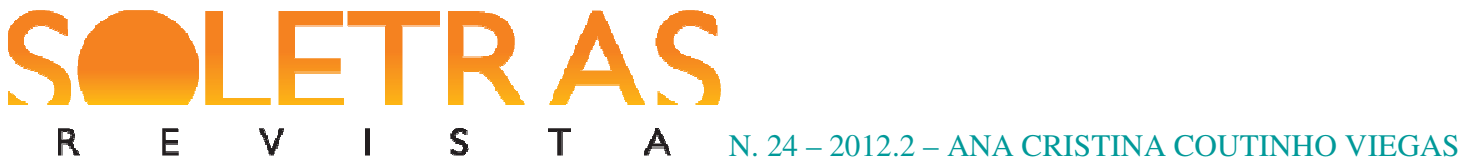

de atuação do eu que se tencionam ou se reforçam, mas que, em todo caso, já não podem ser pensadas isoladamente. $\mathrm{O}$ autor é considerado como sujeito de uma performance, de uma atuação, um sujeito que "representa um papel" na própria "vida real", na sua exposição pública, em suas múltiplas falas de si, nas entrevistas, nas crônicas e auto-retratos, nas palestras [...] (KLINGER, 2007, p. 55).

No caso da crônica, o narrador - mais comumente chamado "o cronista" - não pode ser pensado em termos exclusivamente ficcionais. Se em outros gêneros como o romance assistese ao crescimento de uma produção em primeira pessoa que vem reconfigurando as noções de autor e narrador, a crônica tradicionalmente aponta para um "real", ou melhor, sugere uma identidade entre narrador e autor.

Em depoimento gravado em outubro de 1976 no Museu da Imagem e do Som, no Rio de Janeiro, Clarice Lispector declara não gostar de escrever crônicas Muitas vezes seu espaço no jornal era preenchido com anotações que seriam usadas em seus livros:

MARINA COLASSANTI: Muitos trechos do teu trabalho no Jornal do Brasil eu reencontrei depois em Água viva. Você usava ali muitas anotações, não é, Clarice?

CLARICE LISPECTOR: Claro! Eu estava escrevendo o livro e detestava fazer crônicas, então eu aproveitava e publicava. E não eram crônicas, eram textos que eu publicava (MONTERO; MANZO, 2005, p. 148).

De acordo com Carlos Heitor Cony, Rubem Braga justificava sua militância na crônica por condenar a falta de vida na imprensa em geral, ou seja, tudo que é veiculado nos jornais ou nas revistas, das condições do tempo ao desempenho das bolsas, deve ser "útil" ao leitor, aquilo que, nas redações, é chamado de "serviço" (CONY, 1998). Na contramão da utilidade prevista na linguagem jornalística, Clarice Lispector pertenceria ao grupo ao qual Cony chamou de cronistas "sem assunto", "sem informação" e "sem outro serviço que não o estilo mais sofisticado que só será apreciado por determinados leitores" (CONY, 1998, s/p).

Textos mais longos, que foram posteriormente publicados como contos, pequenos fragmentos que constituíam anotações para seus futuros romances, pequenas peças de puro exercício estético, enfim, o universo múltiplo das crônicas de Clarice Lispector, mesmo passadas algumas décadas, continua a desafiar tentativas de definir esse gênero aparentemente despretensioso.

Como nos lembra a própria escritora, "às vezes começa-se a brincar de pensar e eis que inesperadamente o brinquedo é que começa a brincar conosco" (LISPECTOR, 1999a, p. 24). 


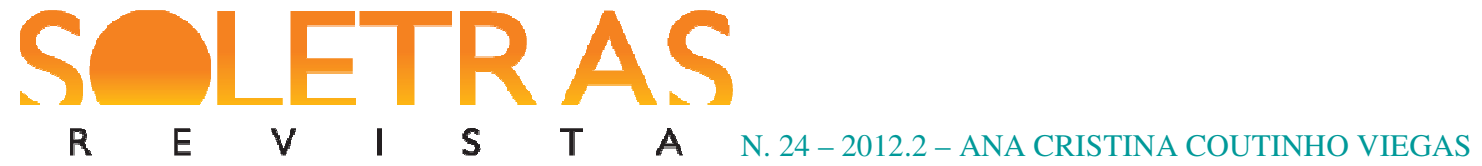

Esses pequenos brinquedos espalhados pelas páginas dos jornais ganharam vida e compõem um mosaico de textos fundamentais para a compreensão do projeto artístico de Clarice Lispector, na medida em que ensaiam teorizações e propõem rupturas que caracterizam sua obra como um todo.

Além disso, dão crônica também.

\section{Referências bibliográficas:}

CANDIDO, Antonio. A vida ao rés-do-chão. In: CANDIDO, Antonio et alii. A crônica: o gênero, sua fixação e suas transformações no Brasil. Campinas, SP: UNICAMP; Rio de Janeiro: Fundação Casa de Rui Barbosa, 1992, p. 13-22.

CONY, Carlos Heitor. A crônica como gênero e como antijornalismo. Folha de São Paulo, 16 de outubro de 1998. http://vidacronica.wordpress.com/2008/05/14/a-cronica-como-genero-ecomo-antijornalismo. Acesso em 05 de novembro de 2012.

JAUSS, Hans Robert. A história da literatura como provocação à teoria literária. São Paulo: Ática, 1994.

LISPECTOR, Clarice. A descoberta do mundo. Rio de Janeiro: Rocco, 1999a.

De corpo inteiro. Rio de Janeiro: Rocco, 1999b.

MONTERO, Teresa (Org.). Correspondências: Clarice Lispector. Rio de Janeiro: Rocco, 2002.

MONTERO, Teresa; MANZO, Lícia (Org.). Outros escritos. Rio de Janeiro: Rocco, 2005.

GOTLIB, Nádia Batella. Clarice: uma vida que se conta. 3. ed. São Paulo: Ática, 1995.

KLINGER, Diana Irene. Escritas de si, escritas do outro: o retorno do autor e a virada etnográfica. Rio de Janeiro: 7 Letras, 2007.

LISPECTOR, Clarice. Laços de família. 11 ed. Rio de Janeiro: José Olympio, 1979.

A maçã no escuro. Rio de Janeiro: Francisco Alves, 1961.

ROCHA, Fátima Cristina Dias. Clarice Lispector paisagista. In: VALLADARES, Henriqueta do Coutto Prado (Org.). Paisagens ficcionais: perspectivas entre o eu e o outro. Rio de Janeiro: 7 Letras, 2007, p. 43-60.

SABINO, Fernando (Org.). Cartas perto do coração: Fernando Sabino, Clarice Lispector. 3. ed. Rio de Janeiro: Record, 2001.

SANT'ANNA, Sérgio. Breve história do espírito. São Paulo: Companhia das Letras, 1991. 


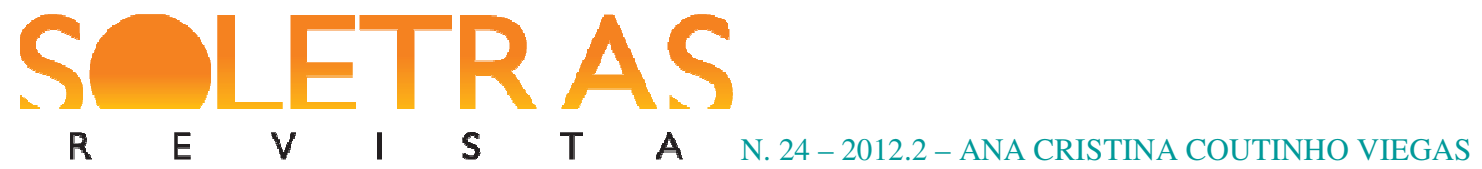

SARAMAGO, José. Ensaio sobre a cegueira. São Paulo: Companhia das Letras, 2004.

STAIGER, Emil. Conceitos fundamentais da poética. Rio de Janeiro: Tempo Brasileiro, 1975.

WELLEK, René; WARREN, Austin. Teoria da literatura. 2. ed. Lisboa: Publicações EuropaAmérica, 1971.

\title{
A female writer as a professional of writing in Brazil: a reading of Clarice Lispector's chronicles
}

\begin{abstract}
Clarice Lispector was a professional writer who, under financial pressure, could not afford not to work for the press. By following this path in her career, Clarice Lispector had a reasonable presence in newspapers and magazines. The present research focuses on her chronicles published in Jornal do Brasil between the years of 1967 and 1973. After Clarice Lispector's death, her chronicles were gathered and published in a book called A descoberta do mundo. The chronicle, which is defined as a hybrid genre, lying in the borderline between journalism and literature, is used many times as a space for enacting subjectivities and proposing metalinguistic reflections. Many of these texts deal with what is trivial and take an unpretentious posture. However, they comprise an important exercise of critique and selfcritique. In Clarice Lispector's case, the transgression mark present in her novels and short stories is once again found in these short texts produced against the clock.
\end{abstract}

Key words: Clarice Lispector. Chronicles. Literary genres.

Recebido em: 03 de dezembro de 2012.

Aprovado em: 28 de dezembro de 2012 . 